\title{
Space speaks: A portrait of an early childhood centre and the affordances provided by the learning environment
}

\author{
Katrina McChesney ${ }^{1}$ \& Jeanette Clarkin-Phillips ${ }^{2}$ \\ ${ }^{1}$ University of Waikato, Tauranga \\ ${ }^{2}$ RMIT University, Melbourne \\ k.mcchesney@waikato.ac.nz / jeanette.clarkin-phillips@rmit.edu.au
}

\begin{abstract}
The quality of early childhood education and care fundamentally depends on teachers' wise practice. However, the environments in which that education and care occur can influence, inform, and shape teachers' practice and children and families' experiences. This article draws on a written 'portrait' of the learning environment created at one New Zealand early childhood education (ECE) centre, capturing both physical and non-physical aspects of the environment and highlighting the affordances the environment offered to children and families/whānau. A Reggio Emilia lens is used to inform analysis of the learning environment and the associated affordances. The portrait (available as a supplementary online file) and this article may support practitioners by providing a vision of what can be in terms of early childhood learning environments, and by providing a possible framework for self-review and inquiry.
\end{abstract}




\title{
Space speaks: A portrait of an early childhood centre and the affordances provided by the learning environment
}

\author{
Katrina McChesney ${ }^{1}$ \& Jeanette Clarkin-Phillips ${ }^{2}$ \\ ${ }^{1}$ University of Waikato, Tauranga \\ ${ }^{2}$ RMIT University, Melbourne
}

\section{Introduction}

The quality of early childhood education and care fundamentally depends on teachers' wise practice. However, the environments in which that education and care occur can influence, inform, and shape teachers' practice and children and families' experiences (Arthur, Beecher, Death, Dockett, \& Farmer, 2015; Claxton \& Carr, 2004; Terreni, 2019). Te Whāriki (Ministry of Education, 2017), the Aotearoa New Zealand early childhood curriculum, acknowledges the importance of learning environments that "will support children's learning and development across the strands of the curriculum" (p. 16) and calls for "the whole of the environment [to be] used as a learning resource" (p. 50). This recognition is also captured in the Reggio Emilia philosophy's acknowledgement of the environment as the 'third teacher' - that is, as the third player (alongside the child and the teacher) in any educational interaction (Fraser \& Gestwicki, 2002; Strong-Wilson \& Ellis, 2007). Within this perspective, the learning environment is valued

"because of its power to organize, promote pleasant relationships between people of different ages, create a handsome environment, provide changes, promote choices and activity, and its potential for sparking all kinds of social, affective and cognitive learning." (Malaguzzi, as cited in Gandini, 2012, p. 339)

Within the field of learning environments research, learning environments are understood to "consist conceptually of both social and physical dimensions" (Zandvliet, 2019, p. 64, emphasis added). That is, learning environments involve not only physical dimensions (such as materials, spaces, light, colour, ease of movement, and aesthetics; see Strong-Wilson \& Ellis, 2007) but also affective and interpersonal dimensions (such as relationships, orderliness, safety, individualisation, power-sharing, and equity; see Fraser, 2019). For the purpose of this article, the term "learning environment" (or simply "environment") is understood in this way.

In this article, a Reggio Emilia lens is used to consider one ECE learning environment and its affordances. This lens was selected because of the particular emphasis on high-quality learning environments within the Reggio Emilia philosophy. We acknowledge that the Reggio Emilia approach is monocultural and originates from outside New Zealand, and that simple, unexamined replication of a non-New Zealand model in the New Zealand context is not appropriate (Pohio, 2009). However, a range of aspects of Reggio Emilia are nonetheless highly compatible with Te Whāriki and the New Zealand context:

- the image of the child as capable and competent (Mawson, 2010);

- the role of the teacher in setting up provocations for learning and then engaging in pedagogy that follows the child's lead (Mawson, 2010);

- the recognition that children may express themselves in many different ways (the "hundred languages of children"; Edwards, Gandini, \& Forman, 2011, p. 11; see also Pohio, 2009);

- the value placed on engaging with the local community and its funds of knowledge (Mawson, 2010; Soutar, 2000); 
- the expectation that teachers document children's learning in order to facilitate reflection and to acknowledge the learning's value (Mawson, 2010); and

- the understanding that learning happens through interaction and interrelationships within a community (Soutar, 2000).

Readers interested in further considering Reggio Emilia's compatibility with ECE in Aotearoa NZ are referred to Mawson (2010); Pohio (2009); Soutar (2000); and Terreni (2019).

Using a Reggio Emilia lens, then, this article explores the affordances of the learning environment at one New Zealand early childhood education (ECE) centre. The centre's environment was captured and analysed through a portraiture methodology to highlight physical and non-physical aspects of the learning environment as well as the affordances this environment offered for children and families. This article adds to the field of learning environments, which to date has paid very little attention to early childhood settings (e.g. see the total lack of consideration given by Zandvliet \& Fraser [2019] in their history and synthesis of the learning environments field). In addition, because this particular ECE centre was found to reflect many features of high-quality learning environments, this article and the associated portrait offer an exemplar of wise practice in relation to ECE learning environments in the Aotearoa NZ context. This may be of use to those preparing to become ECE kaiako as well as those working in the profession and seeking support for self-review and inquiry.

\section{Background}

\section{Affordance theory}

Affordances, according to Gibson (1979), are what an environment "provides or furnishes either for good or ill" (p. 127, emphasis in original). Affordances can be positive or negative, depending on the perception of the individual and what they wish to achieve. Gee's (2008) definition of affordances suggests that they are the objects or features of an environment that might be perceived and used by an individual to achieve certain goals.

In the context of early childhood education and care, the learning environment of an ECE setting can either enhance or prohibit experiences for children, influencing their learning, interactions, and relationships. For example, consider the rhythms and routines that form part of an ECE environment. If flexible, these rhythms and routines might support uninterrupted play and learning (positive); however, if inflexible, they might restrict a child's ability to explore, be creative, or have sustained interactions with others (negative). A variety of studies have demonstrated the affordance of the physical environment to provide opportunities for exploration, risk-taking, use of the senses, and creativity (see, for example, Canning, 2010; Davis, 2010; Quayle, 2017).

Importantly, an environment offers affordances through features, artefacts, or objects, which could be material, social, and/or cultural (Clarkin-Phillips, 2016). This means that, although much work to date has focused only on the affordances offered by physical (or material) aspects of an environment, affordances can also be considered in relation to the non-physical aspects of a learning environment.

\section{ECE learning environments in Aotearoa New Zealand}

In terms of the physical features of early childhood education and care environments in Aotearoa New Zealand, centres are required to meet the Education (Early Childhood Services) Regulations (New Zealand Government, 2008) in order to gain an operating licence. These regulations provide 
for a minimum allocation of space per child. In addition, any outdoor equipment provided must meet the New Zealand Playground Equipment and Surfacing Standard (Standards New Zealand, 2015). Beyond these minimum conditions, there is significant variability in the physical environments of New Zealand's ECE settings. Some settings have been purpose-built, while other ECE centres have adapted existing structures (such as residential houses) to create a learning environment. Some settings simply meet the minimum regulations, while others go beyond the requirements and offer expansive areas both indoors and outdoors incorporating architectural 'best practice' design.

In terms of the non-physical features of early childhood environments, the goals specified within Te Whāriki (Ministry of Education, 2017) define the "characteristics of ECE environments and pedagogies" (p. 22) that teachers should work to implement; each goal begins with the statement "Children experience an environment where ..." (pp. 22-23). Most of these goals reflect aspirations for the psychosocial (rather than the physical) learning environment. For example, children's "emotional wellbeing [should be] nurtured" (Wellbeing / Mana Atua); children should know that they "have a place" (Belonging / Mana Whenua); they should be "encouraged to learn with and alongside others" (Contribution / Mana Tangata); and their play should be "valued as meaningful learning" (Exploration / Mana Tūroa). Unlike the minimum standards prescribed for the physical aspects of ECE learning environments, Te Whāriki's goals provide more visionary aspirations for the non-physical aspects of ECE environments.

\section{High-quality ECE learning environments}

While debates may occur about physical considerations such as the optimum provision of space or the most appropriate learning resources for early childhood education and care, it is the teachers' knowledge, philosophies, and pedagogical actions that determine the quality of the programme including both the organisation of the physical space and the creation of a particular socioemotional

climate. Teachers who understand the power of the learning environment to influence children's, teachers' and families' interactions with people, places, and things will endeavour to maximise the opportunities the learning environment (both physical and non-physical) can afford (Arthur et al., 2015).

Looking beyond the NZ-specific Te Whāriki goals for early childhood learning environments (discussed above), the Reggio Emilia philosophy's particular emphasis on the learning environment as the third teacher has led to much international consideration of the features of high-quality early childhood environments (Terreni, 2019). Reggio Emilia educators and researchers have highlighted the following features (Ceppi \& Zini, 1998; Gandini, 2012); the list offers a rich set of aspirations for any early childhood setting.

- Overall softness - an environment with flexibility that allows for intersections between activities, spaces, and people.

- A relational space - an environment rich in relationships, communication, cooperation, and co-exploration.

- Continuity with surrounding environments and social connections - an environment that links to outside/other spaces, relationships (e.g. parents, siblings, or children who previously attended the centre), and wider communities.

- Multiple sensorial experiences - an environment rich in opportunities for exploration and stimulation, including thoughtful use of colour, light, and materials.

- Flexibility and adaptation - an environment that is co-constructed with children and can respond to their interests. 
- Community and participation - an environment that facilitates engagement, conversation, and a sense of belonging.

- Social constructivism - an environment that provides opportunities for the ongoing construction of knowledge within dynamic social interactions and negotiations.

- Narration - an environment in which both philosophies and activities are intentionally narrated (e.g. through photos, learning stories, wall displays, artworks, journals, or artefacts), so that children's and teachers' learning, inquiry, and voices are captured and made visible.

- Intense richness every day - an environment in which the richness of children's everyday activities is noticed, valued, and supported.

It is clear that this list of features captures both physical and non-physical aspects of the learning environment. According to Gandini (2012, p. 323), these features "are based on the fundamental principles of pursuing relationship and constructing educational experiences by observing and listening." The Reggio Emilia features above also align with those identified in other research about effective pedagogy and intentional teaching that incorporates the material, social, and cultural aspects of the learning environment (see, for example, Arthur et al., 2015; Claxton \& Carr, 2004; McLaughlin, Aspden, and McLachlan, 2015).

\section{Research context and aim}

This article draws on a written 'portrait' of the learning environment created at an early childhood centre in Tauranga, New Zealand ${ }^{1}$. Both the portrait and this article focus on how the early childhood centre's learning environment affords and informs the pedagogies and relationships that children and whānau experience.

The environment captured in the portrait is the infant and toddler centre of Greerton Early Learning Centre (GELC), a privately owned full-day early childhood centre in Tauranga, New Zealand ${ }^{2}$. At the time the portrait was developed, GELC operated two centres on neighbouring streets: an infant and toddler centre (licensed for 30 children) and an older children's centre (licensed for 40 children). After two decades operating in repurposed residential houses, the decision was made to close the infant and toddler centre on Emmett Street and amalgamate both centres at what had previously been the older children's site to allow a new, purpose-built facility to be constructed on the old infant and toddler site.

The portrait was developed by the first author as a gift to the GELC staff and community in the period leading up to the closure of the original infant and toddler centre on Emmett Street. The first author's hope was to create a record of the Emmett Street facility before it closed, capturing the physical and non-physical features of the learning environment after two decades of teaching, learning, adaptation, and co-construction with children. In addition to describing the learning environment, the portrait was intended to highlight the affordances this environment offered for teaching, learning, and relationships. Following a request from the centre staff, the portrait is now being published more widely alongside this article as a resource that may be of use to practitioners in other settings.

\footnotetext{
${ }^{1}$ The full portrait is available as a supplementary online file; extracts from the portrait appear within this article.

${ }^{2}$ The centre's name and location and the portrait itself are used with the centre's permission. Staff from the centre have also read and approved this manuscript.
} 


\section{Methods}

Portraiture is a strengths-based, interpretivist research methodology. It combines "systematic, empirical description with aesthetic expression, blending art and science, humanistic sensibilities and scientific rigor" (Lawrence-Lightfoot \& Davis, 1997, p. 3). Portraiture is related to more wellknown qualitative (particularly ethnographic) research approaches (Davis, 2003; Hackman, 2002) but is distinguished by its focus on producing an artistically coherent and aesthetically pleasing output (Davis, 2003). According to Hackman (2002), portraiture is useful within educational research because unlike dense research reports that may "merely sit on a shelf, collecting dust" (p. 58), a research portrait offers a user-friendly presentation of findings that can prompt deeper thinking and reflection by practitioners. In the New Zealand context, portraiture's strengths-based approach also aligns well with the strengths-based philosophies underpinning Te Whāriki (Ministry of Education, 2017) and narrative assessment methods such as learning stories (Carr, 2001).

The aim of (written) research portraiture can be understood by reflecting on its parallels with visual art forms. In terms of visual arts, a photograph offers a precise, exact, direct, but surface-level depiction of a subject. A painted portrait, in contrast, offers a carefully constructed work of art that captures the essence of the subject while also reflecting the artist's positioning and interpretation. The visual artist's own style, thinking, and conceptualisation of the subject are essential to the production of the portrait. Similarly, a written research portrait is not a clinical documenting of a subject such as might be provided by a transcript of an observation within an early childhood centre. Instead, a research portrait is a text that seeks to bring the subject (in this case, the early childhood centre environment) to life and capture what the portraitist sees as the essence of that subject (Lawrence-Lightfoot \& Davis, 1997). The text "is imprinted with the researcher's understanding of and relationship with the individual or site that is represented in the text" (Davis, 2003, p. 199).

The portrait in this article was developed by the first author, who was already connected to the centre and its community as the parent of a child who had attended the older children's centre for approximately two years. However, the portrait captures the infant and toddler centre, drawing on personal experiences, site visits, examination of photographs, and conversations with teachers and parents. Data were collected over a period of two weeks, with the permission of the teaching team. ${ }^{3}$

Data analysis involved identifying themes in terms of how the centre's learning environment offered affordances for pedagogy and relationships. These themes emerged naturally (inductively) from the data collection and analysis - they were not looked for (with preconceived ideas) but rather were

\footnotetext{
${ }^{3}$ This project did not start out as a research endeavour, but simply as a way to gift to the centre a unique and original artefact capturing a season in the GELC community's history. For this reason, institutional ethical approval was not considered necessary when the portrait was being developed; instead, permission was obtained from the teaching team, and then the first author (herself a parent at the centre) spoke as a peer to other parents as well as to the teachers, explaining the intention to develop a portrait and asking for ideas, memories and impressions that could be included. Photographs taken by the first author to inform the development of the portrait were only of the space and of materials (such as learning stories) that were already publicly displayed at the centre (i.e. no photos were taken of children for this purpose). Other photographs used (which did show children) came from the centre's website and Facebook page and were hence already publicly available, with parents having previously consented to their children's images being posted online in these ways. After the portrait was completed and gifted to the centre, it was the desire of the staff at the centre that the portrait (including the centre name and location) be published as a resource for others. Nothing in the portrait identified individual children, families, or staff, and the portrait was already publicly displayed at the centre. In order to facilitate publication, a more academic lens was overlaid on the completed portrait, leading to the Reggio Emilia-informed analyses reported in this article; thus, the portrait itself became the data source for this second layer of analysis.
} 
discovered through the first author's immersion in the data. Then, as the portrait was developed, the list of themes was continually reviewed to ensure that the portrait captured the themes.

Returning to the visual image metaphor, the success criteria for a painted portrait is that, when revealed, the subject feels a sense of recognition - "Ah, yes! This is me!" (Lawrence-Lightfoot \& Davis, 1997). For this research portrait, authenticity checking was conducted by a teacher whose own children also attended the centre. Her response, that "it's like you lived at Emmett Street alongside us for all those years!" (M. Osmond, personal communication, May 16, 2017), supports the validity and authenticity of the portrait.

After the portrait was completed, two further analyses were conducted. The first involved mapping the specific affordances associated with the learning environment that were evident in the portrait. The second involved comparing the learning environment as reflected in the portrait with the list of features of high-quality learning environments identified by Reggio Emilia researchers (Ceppi \& Zini, 1998; Gandini, 2012; see Background).

\section{Results and discussion}

This section identifies and discusses the themes that were identified in the data (in no particular order). We illustrate each theme with extracts from the portrait, and we briefly identify the specific physical and/or non-physical features of the learning environment and the associated affordances related to each theme. At the end of this section, we report the two subsequent analyses that synthesise the themes and affordances identified within the portrait.

\section{Themes identified in the data}

The seven themes identified in the data were:

- Relationships and being known

- Risk and challenge

- Child-centred pedagogy

- Openness, opportunities and flexibility

- Nature

- Intentionality

- Exploration and engagement

It was noteworthy that of the seven themes, just one (nature) was directly focused on physical aspects of the learning environment. Two further themes (risk and challenge / openness, opportunities and flexibility) related to the kinds of resources available in the learning environment but also to what sorts of engagement with those resources was allowed and encouraged, thus bridging both physical and non-physical aspects of the learning environment. The remaining four themes all centred on non-physical aspects of the learning environment. 
Stepping through this gate, one ... steps into a place of nurturing, belonging, and care - a place where children are the centre, the taonga [treasure], the life-blood of all that is and all that happens. ${ }^{4}$

On arriving at the centre, ... each child seeks out their own trusted and beloved key teacher to begin the day with a welcoming, reassuring hug. Both children and parents are greeted personally each day; whānau [families] are known and welcomed here, and children - even the very youngest - are respected as being worthy of authentic acknowledgement and communication.

Boxes of the children's learning story folders are available under a window, deliberately arranged with the front covers facing forwards to allow children to flip through and find the book that has their own picture and name on the front. I am known here; I am seen here; I belong here.

The data suggested that in this centre, relationships are valued. Teachers take deliberate steps to create a sense of belonging and connection for every child, parent, and whānau (family) member. Thus, the teachers' philosophies, pedagogies, and related actions - all non-physical features of the learning environment - afford children and parents/whānau a sense of belonging, being known, and being valued. According to McLaughlin et al. (2015, p. 31), "relationships are at the heart of early childhood education principles, curriculum and pedagogy"; it was evident that a key part of the learning environment at this centre was the teachers' enactment of the kinds of relational practices McLaughlin et al. discuss.

\section{Theme 2: Risk and challenge}

Children climb, crawl, jump, balance, ride bikes, hide, pretend, and negotiate ideas, enjoying the unlimited scope offered by the planks of wood, padded mats, and portable climbing boxes that are available in this space.

The ramp ... speaks of the risk, challenge, and belief in children's abilities that are treasured here; many toddlers have spent countless hours zooming down this ramp on bikes, instinctively learning to swerve and brake to avoid colliding with either the infant whare [house] or the infants themselves who may be exploring the area.

A rope swing hanging from the other side of the tree offers a reminder that there is always another challenge to be explored; another goal to reach for; another reason to practice and persevere.

The data indicated that, at this centre, children are seen as "competent and confident learners" (Mawson, 2010; Ministry of Education, 2017) and so are allowed - and offered opportunities - to stretch their bodies and minds, trusting their internal instincts for what is safe and appropriate for them at any given time. Within this theme, the portrait specifically illustrates how physical aspects of the environment (including the provision of flexible and challenging materials) afford opportunities for children to explore and extend their physical abilities and their associated dispositions. Nonphysical aspects of the environment are also important here: namely, the value that is placed on opportunities for children to engage in risky, challenging play, and the pedagogical actions that support this (providing materials; allowing children to experiment and make their own judgements).

\footnotetext{
${ }^{4}$ Sections formatted in this way are extracts from the written portrait.
} 
This theme aligns with other New Zealand research (e.g. Hanrahan \& Duncan, 2019; Quayle, 2017) that has highlighted the benefits of learning environments that include risk and challenge.

\section{Theme 3: Child-centred pedagogy}

The children, absorbed in their exploration and enjoyment of this side garden, are quietly watched, supported and talked with by the wise teaching staff.

While the teachers are always present and engaged, watching, communicating, caring, and comforting, it is the children who lead what goes on here. Each child's daily rhythms for eating, sleeping, and care moments are accepted and maintained during their days at Emmett Street. During their awake times, the children are free to pursue their own interests and learning intentions and to choose where they want to spend their time.

This theme relates to non-physical aspects of the learning environment: the teachers' pedagogical practices and, in particular, the ways teachers refrain from intervening in or controlling children's activities but instead allow space for (afford) teaching and learning to emerge from children's instincts and interests. The data indicated that teachers at this centre notice, recognise, and respond to children's activity (Ministry of Education, 2004) in ways that scaffold and extend learning and exploration (Claxton \& Carr, 2004). The child-centred approach to physical care moments also affords agency and autonomy to children as their own rhythms are respected and valued (Christie, 2011). This pedagogical approach aligns closely with the Reggio Emilia philosophy (Mawson, 2010) but also with the "relational play-based pedagogy" identified in Aotearoa NZ by Hedges and Cooper $(2018$, p. 370) as "a sophisticated and thoughtful theoretically informed blending of play, learning and teaching."

\section{Theme 4: Openness, opportunities and flexibility}

This space is flexible, enjoyed in different ways depending on the seasons and the interests of the children.

The deck serves, at various times, as a picnic venue, an art studio, a castle, and a site for celebrations and hui ... Even the rails of the deck's balustrade tell stories of the children who have painted the rails, banged on them to make music, peeked through them, and pulled themselves up to help them learn to stand.

Children have also helped shape the space, initiating new ideas, participating in the real work of developing the indoor and outdoor spaces, and contributing the taonga that fill the walls and garden.

Closely related to the child-centred pedagogy described above, the data indicated that in this centre, spaces and activities are fundamentally flexible. The teaching team are open to children's interests and families' needs, and this input from children and whānau is evident in both the makeup and the use of the physical environment. There are multiple layers of affordance here: the teachers' approaches (non-physical aspects of the learning environment) afford space for children and families to contribute ideas and influence culture and practice at the centre; input from children and families affords new opportunities and changes within the physical environment; and the physical space affords flexibility so that the environment can be used in a range of diverse ways, creating 
opportunities for learner agency as well as rich learning to occur. This theme aligns with Hedges and Cooper's (2018, p. 370) "relational play-based pedagogy" as well as Smith's (2007, p. 155) discussion of the "climate of reciprocity" that Te Whäriki encourages. This theme also links to the interest in flexible learning spaces in the schooling sector both in New Zealand (Benade, 2015) and internationally (Zandvliet, 2019), with flexibility and openness (in space, in materials, and/or in pedagogy) being understood to offer greater affordances than more rigid alternatives.

\section{Theme 5: Nature}

Stepping through this gate, one steps into nature, embraced by the shady protection and the gentle rustling sounds of the leafy cherry blossom tree.

The whole garden is abundant in natural sights, smells, and textures, with its long grasses, rocks, low camellia hedge, water, harakeke bushes, tall trees, and even a small mandarin tree.

Natural light streams in through the large wood-framed windows; the open layout lets children move freely between the spaces in this whare [house] and the outside areas.

At the back of the property is a second garden area, full of further opportunities to explore, investigate, experience, and try out new or ongoing challenges. Rain, hail, or shine, this 'yes' space is full of activity.

Rocks, tree stumps, and gentle mounds in the grass invite adventure and inquiry. A low planter boxdeliberately at child level, like everything in this place - offers the bright colours of flowering impatiens and ripe strawberries; the textures of earth, water, leaves, and flowers; the smells of fresh basil and rosemary; the excitement of hunting for big, fat, wriggly worms.

The data clearly indicated that nature is an essential and valued element of the GELC learning environment. Nature is never off-limits: Natural objects, images, and light are allowed into the two whare (buildings), and children are always allowed out into nature (whatever the weather!). Thus, at this centre, the way the physical environment has been shaped and developed over time affords extensive experiences with nature, and these experiences then support (afford) risk, challenge, exploration, and creativity. This theme aligns with other research that has explored the value and affordances of nature in early childhood learning environments (e.g. Alcock \& Ritchie, 2018; Canning, 2010; Hanrahan \& Duncan, 2019; MacQuarrie et al., 2015; Quayle, 2017; Terreni, 2019).

\section{Theme 6: Intentionality}

In one sense, it could be anyone's Kiwi backyard; yet this space has been thoughtfully developed in order to maximise the invitations to play and to learn that are provided by the natural resources.

Up at adult level, the items on the walls of the infant whare reflect the intentionality, respect, and love that characterise what goes on here. Photos of the children are displayed along with the stories behind each of their names, and a reminder of the unspoken but profound question asked by children the world over: Do you know me? The teacher inquiries that are documented around the walls of the whare [house] celebrate authenticity and identity. 
Children's artwork is thoughtfully displayed: paintings framed in thin sticks of driftwood; sheets of calico decorated by many small hands; twigs dipped in paint or glitter that previously adorned a Christmas tree constructed and decorated by the children.

A small number of well-chosen, well-loved toys and books lie on the floor around the edges of the room - accessible at child level but not in the way of the important work of learning to move.

There has sometimes been tension between child-centred pedagogies and intentional acts of teaching in early childhood education (McLaughlin et al., 2015), but this portrait reveals teachers exercising their intentionality in the design of the learning environment and then being ready to notice, recognise, and respond as children explore that environment (Ministry of Education, 2004; Strong-Wilson \& Ellis, 2007). This theme thus provides further illustration of the "middle ground" captured in Hedges and Cooper's (2018, p. 370) relational play-based pedagogy. The data indicated that the teachers at this centre are neither passive supervisors nor active directors of learning but instead respond with intentionality and professional expertise to children's initiative and activity. Thus, the teachers' intentional practice shapes a rich physical environment, and the child-centred culture (a non-physical dimension of the learning environment) affords freedom for learner agency and rich learning as children explore the environment.

\section{Theme 7: Exploration and engagement}

Children explore and construct meaning around daily life, family roles, and identity through their imaginative play in the whānau [family] area, with its child-sized bed, doll-sized high chair and cot, dressers, and baskets of dress-up clothes and homewares. Musical instruments, wooden cars, magnets, puppets, simple but sturdy dolls houses are all available, but are not the centre of attention; children frequently bring in treasures from outside - sticks, rocks, shells, flowers, bark, driftwood - that are just as valuable and captivating.

Children naturally respond to the large sand pit's invitation to inquiry and imagination, enjoying their work under the shelter of large shade sails. The gravel pit offers another sensory experience for little explorers, who are intent on their scooping, pouring, driving, spreading, touching, and patting. In summer, the water feature at the back of the garden is full of children splashing, crawling, balancing, and climbing in the tiered ponds and enjoying the feel of the water running down from one level to the next. Getting wet, sandy, muddy, or grass-stained is welcomed as a natural part of exploring and learning - and the children delight in it.

Given the rich physical environment and the child-centred culture discussed above, it was no surprise that the data also emphasised children's active exploration of and engagement in the GELC environment. This finding aligns with the importance of Exploration (Mana Aotūroa) as one of the five strands within Te Whăriki (Ministry of Education, 2017). The portrait captures some of the range of materials and spaces provided within the physical environment and shows how these physical resources afforded children opportunities to become absorbed in learning experiences; this connects to the Reggio Emilia approach in terms of the resources in the learning environment forming provocations for children's play and learning (Strong-Wilson \& Ellis, 2007).

\section{Analyses of themes and affordances}

The discussion above presented the seven themes identified within the portrait. This section reports on and discusses two additional analyses: an examination of the affordances associated with the 
learning environment and a comparison of the portrait themes with a Reggio Emilia conceptualisation of a high-quality learning environment.

Across the seven themes found in the portrait, a range of affordances were identified. These affordances were categorised as relating to six key elements, most of which reflected non-physical aspects of the learning environment:

- Teacher knowledge, philosophies, and practices

- Children/families' affective experiences

- Physical environment

- Child voice/agency/empowerment

- Opportunities to experience nature

- Opportunities to learn and grow

The first of these elements - teacher knowledge, philosophies, and practices - merits particular attention. At the time this portrait was developed, all of the full-time staff at the centre were fully qualified, New Zealand-registered teachers who were actively committed to "basing their practice inside sound research and theory" with a shared pedagogical philosophy that developed "out of deeply thoughtful consideration of what is the essence of the culture of learning and teaching in [their specific] setting" (L. Sands, personal communication, 22 June 2020). While current legislation does not require $100 \%$ qualified staffing in NZ early childhood centres, both national and international evidence repeatedly demonstrate that higher proportions of qualified staff are associated with improved quality outcomes as well as improved outcomes for children (see, for example, Manning et al., 2019; Mitchell, 2019). The quality of the learning environment captured in the present portrait and the particular research-informed and reflective teacher knowledge, philosophies, and practices contributing to that learning environment thus provide a compelling example of what can be done by a group of highly skilled, highly qualified early childhood teachers.

Figure 1 maps the types of affordances identified among the elements listed above. Each arrow shows the direction of the affordance. Of the six elements, sources of affordance were: teacher knowledge, philosophies, and practices; child voice/agency/empowerment; the physical environment; and opportunities to experience nature. Outcomes of affordances were: children/families' affective experiences; child voice/agency/empowerment; the physical environment; opportunities to experience nature; and opportunities to learn and grow. 


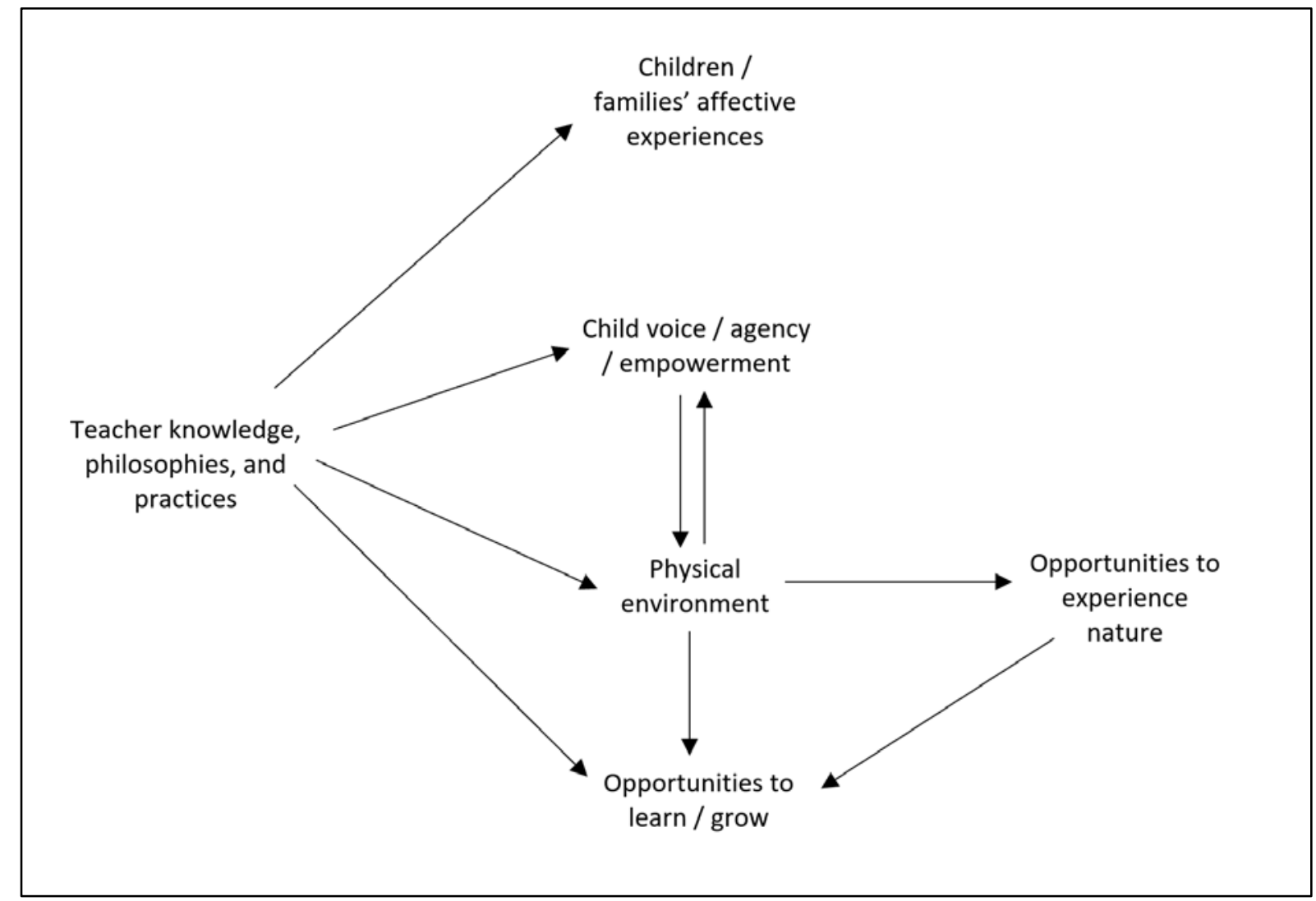

Figure 1. Map of affordances identified in the learning environment.

In addition to the mapping above, a deductive analysis revealed that, together, the seven themes identified in the portrait connect to each of the features of high-quality early childhood education and care environments identified within the Reggio Emilia tradition (Ceppi \& Zini, 1998; Gandini, 2012; see Literature Review section). Figure 2 shows how the portrait themes intersect with the Reggio Emilia features. This analysis once again demonstrates the quality of education and care that can be provided by a highly skilled team of practitioners. The staff had not specifically set out to meet the Reggio Emilia criteria in developing their learning environment, but instead their intentional enactment of research-informed approaches, combined with deep and frequent reflection and inquiry (both individual and collaborative), led to the centre's learning environment being shaped over time into one that comprehensively aligned with literature-based aspirations (such as the Reggio Emilia criteria) for what a high-quality learning environment could and should be like. 


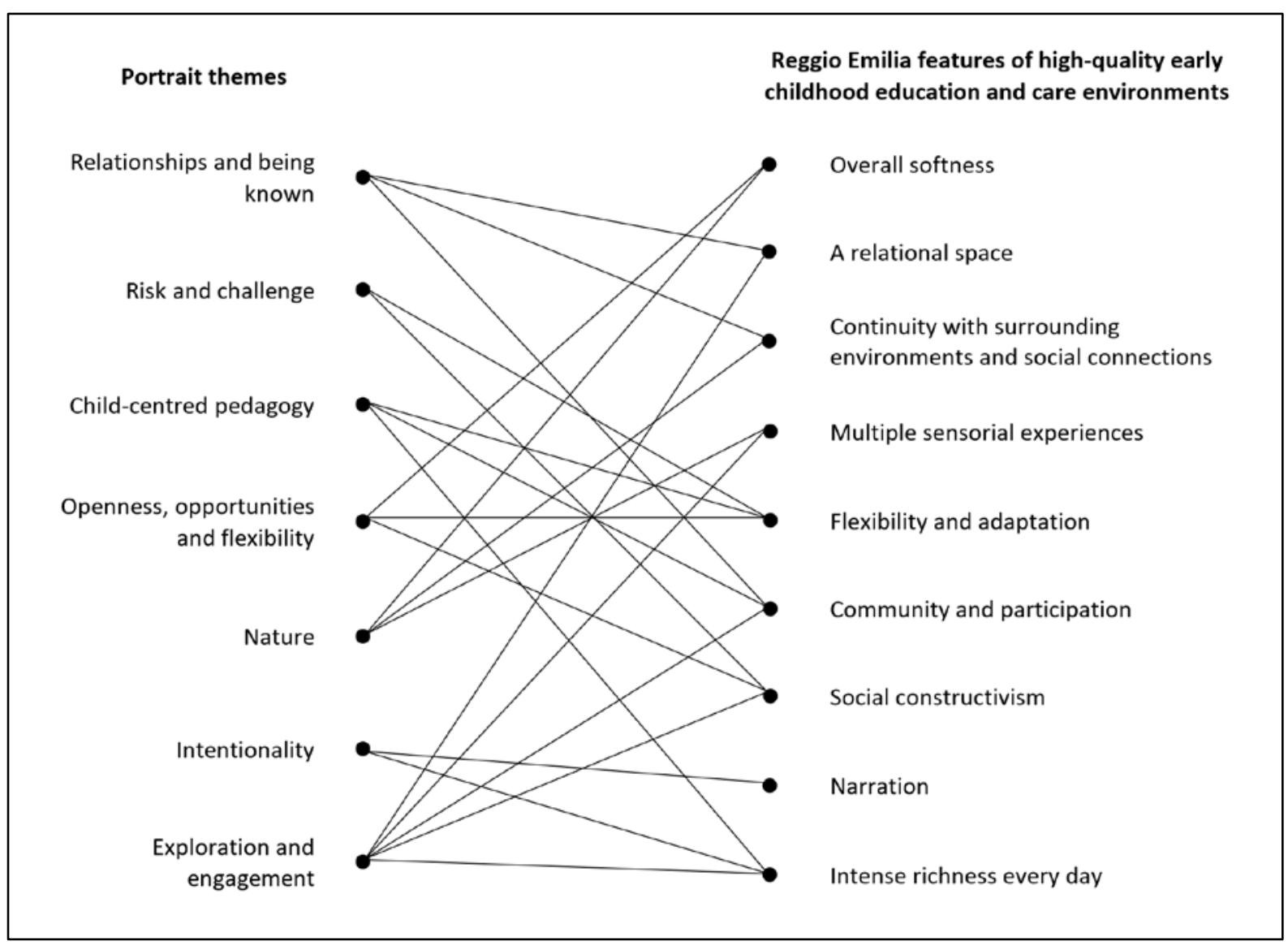

Figure 2. Connections between the portrait themes and the Reggio Emilia features of high-quality early childhood education and care environments

\section{Implications}

The portrait reported in this article, the themes identified in the portrait, and the findings in relation to the affordances of the ECE centre's learning environment may be of use to practitioners in several ways.

First, the portrait and this article may provide a vision of what can be in terms of early childhood learning environments. It is easy to become caught up in the minimums of practice - the requirements we must meet within our spaces in terms of health and safety, licensing, and compliance (Delany, 2011). It is also easy to hold onto a narrow conceptualisation of learning environments that only focuses on physical dimensions. Many snapshots of effective ECE practice in Aotearoa NZ have already been collected (see, for example, https://tewhariki.tki.org.nz/en/weavingte-whariki/), but few of these specifically illustrate early childhood learning environments and their potential as the 'third teacher'. We hope that the portrait reported in this article constitutes a resource that can help address this gap and spark reflection, creativity, and ongoing improvement in ECE learning environments.

Second, the themes and affordances identified in this paper may provide a more specific framework for self-review and inquiry. The themes from the portrait as well as the sources and outcomes of the affordances mapped in Figure 1 could be considered in relation to any other centre's learning environment. In terms of the portrait themes, practitioners could consider: To what extent does our centre reflect each of these themes? Which aspect/s might we want to strengthen? What can we see in the GELC portrait that illustrates this aspect working well? How might this aspect be developed in 
our own setting, in ways that are authentic for our own children and community? In terms of the affordances identified in Figure 1, practitioners could consider: To what extent do we have the 'building blocks' (the sources of affordance) in place in our setting? Are we seeing similar outcomes from these sources of affordance? If not, why not? What could we do to maximise the affordances of our learning environment? Affordances and other features within a learning environment by no means guarantee particular outcomes for children or families (Claxton \& Carr, 2004), but they are nonetheless important building blocks to consider in the continual development and enhancement of a learning environment (Strong-Wilson \& Ellis, 2007).

It is important to acknowledge that this article, and the portrait, reflect just one early childhood setting, and that other settings will necessarily vary. There is not just one way to create a highquality learning environment, but we argue that there are principles that can be helpful across a range of contexts. The goals of Te Whāriki, as well as the Reggio Emilia principles discussed in this article, can serve this purpose. Further, even if the learning environment described in this article - or another environment of similar quality - were 'transplanted' into other ECE settings, its power would still be limited by the wisdom and skill of the teaching staff. Nonetheless, learning environments still merit reflection and critique, and this article provides one example of how this can occur in terms of both physical and non-physical elements.

Further research could add to a body of such exemplars and analyses of early childhood learning environments. Incorporating children's voices would add a rich layer of meaning, as children's own goals could be identified in order to allow consideration of the affordances provided by the learning environment in relation to these goals. Alternatively, focused observation of how children relate and interact with others within the ECE setting could allow social relationships - another important dimension of a learning environment - to be mapped.

According to Arthur et al. (2015, p. 354), "every early childhood environment abounds with unspoken messages for each child and adult who enters the setting." A strength of portraiture as a research methodology is its ability to support reflection and improvement by capturing a potentially familiar subject in a fresh way (Hackmann, 2002). We hope that this portrait and the associated discussion in this article support early childhood practitioners to reflect on the learning environments they create and to consider how these can be best harnessed to afford optimal opportunities for children and their families/whānau.

Ko te tamaiti te pūtake o te kaupapa.

The child is the heart of the matter. 


\section{References}

Alcock, S., \& Ritchie, J. (2018). Early childhood education in the outdoors in Aotearoa New Zealand. Journal of Outdoor and Environmental Education, 21, 77-88. https://doi.org/10.1007/s42322-017-0009-y

Arthur, L., Beecher, B., Death, E., Dockett, S., \& Farmer, S. (2015). Programming and planning in early childhood settings (6th ed). Victoria, Australia: Cengage Learning.

Benade, L. (2015). The transformative educative prospects of flexible learning environments. New Zealand Journal of Teachers' Work, 12(1), 9-13.

Canning, N. (2010). The influence of the outdoor environment: Den-making in three different contexts. European Early Childhood Education Research Journal, 18(4), 555-566. https://doi.org/10.1080/1350293X.2010.525961

Carr, M. (2001). Assessment in early childhood settings: Learning stories. London, UK: Paul Chapman.

Ceppi, G., \& Zini, M. (Eds). (1998). Children, spaces, relations: Meta-project for an environment for young children. Reggio Emilia, Italy: Reggio Children.

Christie, T. (2011). What does 'respect' mean for infants and toddlers in early childhood centres? The First Years: Ngā Tau Tuatahi: New Zealand Journal of Infant and Toddler Education, 13(1), 16-21.

Clarkin-Phillips, J. G. (2016). Fighting the odds to make it even: Mapping an affordance ecosystem in a kindergarten community (Doctoral thesis, University of Waikato, New Zealand). Retrieved from https://researchcommons.waikato.ac.nz/handle/10289/9991

Claxton, G., \& Carr, M. (2004). A framework for teaching learning: The dynamics of disposition. Early Years, 24(1), 87-97. https://doi.org/10.1080/09575140320001790898

Davis, J. H. (2003). Balancing the whole: Portraiture as methodology. In P. M. Camic, J. E. Rhodes, \& L. Yardley (Eds), Qualitative research in psychology: Expanding perspectives in methodology and design (pp. 199-217). Washington, DC: American Psychological Association.

Davis, J. M. ( 2010). What is early childhood education for sustainability? In J.M. Davis (Ed.), Young children and the environment: Early education for sustainability. (pp 21-42). Sydney, Australia: Cambridge University Press.

Delany, K. (2011). Waking the 'third teacher': The whys and hows (Te Whāriki: Principle to practice). Retrieved from http://www.elp.co.nz/files/delany k waking the third teacher.pdf

Edwards, C., Gandini, L., \& Forman, G. (Eds.) (2012). The hundred languages of children: The ReggioEmilia experience in transformation. Santa Barbara, CA: Praeger.

Fraser, B. J. (2019). Milestones in the evolution of the learning environments field over the past three decades. In B. J. Fraser \& D. B. Zandvliet (Eds.), Thirty years of learning environments (pp. 1-19). Leiden, The Netherlands: Brill Sense.

Fraser, S., \& Gestwicki, C. (2002). Authentic childhood: Exploring Reggio Emilia in the classroom. Albany, NY: Delmar/Thomson Learning. 
Gandini, L. (2012). Connecting through caring and learning spaces. In C. Edwards, L. Gandini, \& G. Forman (Eds.), The hundred languages of children: The Reggio-Emilia experience in transformation (pp. 317-341). Santa Barbara, CA: Praeger.

Gee, J. (2008). A socio-cultural perspective on opportunity to learn. In P. A. Moss, D.C. Pullin, J. G. Gee, E. H. Haertel, \& L. J. Young (Eds.), Assessment, equity, and opportunities to learn (pp.76108). Cambridge, UK: Cambridge University Press.

Gibson, J. J. (1979). The ecological approach to visual perception. Boston, MA: Houghton Mifflin

Hackman, D. G. (2002). Using portraiture in educational leadership research. International Journal of Leadership in Education, 5(1), 51-60. https://doi.org/10.1080/13603120110057109

Hanrahan, V., \& Duncan, K. (2019). Risky outdoor play in early childhood: Feel the fear and learn from it. He Kupu, 6(2), 14-19.

Hedges, H., \& Cooper, M. (2018). Relational play-based pedagogy: Theorising a core practice in early childhood education. Teachers and Teaching, 24(4), 369-383. https://doi.org/10.1080/13540602.2018.1430564

Lawrence-Lightfoot, S. \& Davis, J. H. (1997). The art and science of portraiture. San Francisco, CA: Wiley.

MacQuarrie, S., Nugent, C., \& Warden, C. (2015). Learning with nature and learning from others: Nature as setting and resource for early childhood education. Journal of Adventure Education and Outdoor Learning, 15(1), 1-23. https://doi.org/10.1080/14729679.2013.841095

Manning, M., Wong, G. T. W., Fleming, C. M., \& Garvis, S. (2019). Is teacher qualification associated with the quality of the early childhood education and care environment? A meta-analytic review. Review of Educational Research, 89(3), 370-415. https://doi.org/10.3102/0034654319837540

Mawson, B. (2010). Finding our way: Interpreting Reggio in a New Zealand context. Early Childhood Folio, 14(1), 18-22.

McLaughlin, T., Aspden, K., \& McLachlan, C. (2015). How do teachers build strong relationships? A study of teaching practices to support child learning and social-emotional competence. Early Childhood Folio, 19(1), 31-38. https://doi.org/10.18296/ecf.0006

Ministry of Education. (2004). An introduction to Kei Tua o te Pae: He whakamōhiotanga ki Kei Tua o te Pae (book 1). Wellington, New Zealand: Learning Media.

Ministry of Education. (2017). Te whāriki: He whāriki mātauranga mō ngā mokopuna o Aotearoa: Early childhood curriculum. Wellington, New Zealand: Ministry of Education.

Mitchell, L. (2019). Turning the tide on private profit-focused provision in early childhood education. New Zealand Annual Review of Education, 24, 75-89. https://doi.org/10.26686/nzaroe.v24i0.6330

New Zealand Government. (2008). Education (early childhood services) regulations 2008. Retrieved from http://www.legislation.govt.nz/regulation/public/2008/0204/latest/DLM1412501.html 
Pohio, L. (2009). Reggio Emilia pedagogy in early childhood education: How can this approach enhance visual arts experiences in New Zealand? He Kupu, 2(2), 10-18.

Quayle, K. (2017). Young children's creativity in outdoor settings. Early Childhood Folio, 21(2), 28-32. https://doi.org/10.18296/ecf.0042

Soutar, B. (2000). Nurturing mana and tapu - Italian style. Early Education, 22, 7-10.

Smith, A. (2007). Children and young people's participation rights in education. International Journal of Children's Rights, 15(1), 147-164. https://doi.org/10.1163/092755607X181739

Standards New Zealand. (2015). NZS 5828:2015 New Zealand standard: Playground equipment and surfacing. Retrieved from https://shop.standards.govt.nz/catalog/5828\%3A2015\%28NZS\%29/view

Strong-Wilson, T, \& Ellis, J. (2007). Children and place: Reggio Emilia's environment as third teacher. Theory Into Practice, 46(1), 40-47. https://doi.org/10.1080/00405840709336547

Terreni, L. (2019). The art of successfully designing a quality early child learning environment. International Art in Early Childhood Research Journal, 7, 1-18.

Zandvliet, D. B. (2019). Looking back and looking forward. In B. J. Fraser \& D. B. Zandvliet (Eds.), Thirty years of learning environments (pp. 59-71). Leiden, The Netherlands: Brill Sense.

Fraser, B. J., \& Zandvliet, D. B. (Eds.) (2019). Thirty years of learning environments. Leiden, The Netherlands: Brill Sense. 